\title{
Além do Flashback. Estéticas Audiovisuais do Fenômeno da Lembrança
}

\author{
Alex Damasceno \\ Doutorando em Comunicação e \\ Informação na Universidade Federal \\ do Rio Grande do Sul (UFRGS). \\ Bolsista Capes. Mestre em Ciências \\ da Comunicação pela Universidade \\ do Vale do Rio dos Sinos (Unisinos). \\ Especializado em Cinema pela Unisinos. \\ Bacharel em Comunicação Social - \\ Jornalismo pela Universidade Federal \\ do Pará (UFPA). Membro dos Grupos de \\ Pesquisa Processocom e Gpesc. \\ E-mail: damasceno-alex@ig.com.br
}

Resumo: Este artigo é inspirado na articulação entre cinema e memória proposta nos ensaios de Munsterberg. Analisamos a representação audiovisual da lembrança, além de sua vinculação ao procedimento narrativo do flashback, objetivando uma abordagem estética. Do lado do audiovisual, nos baseamos no pensamento de Xavier acerca das diferentes proposições ideológicas que orientam a prática cinematográfica. Em relação à memória, trabalhamos a partir da descrição fenomenológica de Bergson e das apropriações de Deleuze. A partir desses marcos conceituais, investigamos três estéticas: o naturalismo, que fabrica flashbacks a partir de convenções na decupagem e mise-en-scène; o realismo, em que a natureza virtual do passado é herdada diretamente de uma lembrança pura; o antirrealismo, que utiliza procedimentos impressionistas e expressionistas na tentativa de superar a dualidade entre presente e passado.

Palavras-chave: estética; audiovisual; lembrança; flashback.

Abstract: This article is inspired by the joint between cinema and memory proposed by Munsterberg. We analyze the audiovisual representation of the memory, beyond its connection to the flashback narrative procedure, aiming an aesthetic approach. On the audiovisual side, we rely on Xavier's thought about the different ideological propositions that guide film practice. Regarding memory, we work from the phenomenological description of Bergson and the appropriations of Deleuze. From these conceptual frameworks, we investigate three aesthetics: naturalism, which manufactures flashbacks from conventions in decoupage and mise-en-scène; realism, in which the virtual nature of the past is inherited directly from a pure memory; and anti-realism, which uses impressionists and expressionists procedures in an attempt to overcome the duality between past and present.

Keywords: aesthetic; audiovisual; memory; flashback.

\section{Introdução}

Neste artigo, investigamos a representação audiovisual da lembrança em suas diferentes estéticas. Esse tipo de representação foi descrito por Hugo Munsterberg (1991) ainda nos primórdios da teoria do cinema: 
as leis do mundo exterior, obedece as da mente. Mas o papel da memória e da imaginação na arte do cinema pode ser ainda mais rico e significativo. A tela pode refletir não apenas o produto das nossas lembranças ou da nossa imaginação, mas a própria mente dos personagens. A técnica cinematográfica introduziu com sucesso uma forma especial para esse tipo de visualização. Se um personagem recorda o passado - um passado que pode ser inteiramente desconhecido do espectador, mas que está vivo na memória do herói ou da heroína - os acontecimentos anteriores não surgem na tela como um novo conjunto de cenas, mas ligam-se à cena presente mediante lenta transição (MUNSTERBERG, 1991: 38-39).

Munsterberg associa essa visualização do ato de lembrar ao procedimento audiovisual do cutback (jargão que equivale atualmente ao termo flashback), um recurso analéptico (o que já é explicitado na tradução do inglês: "cortar para trás") que, no âmbito da narrativa, "pode servir a muitos propósitos" (MUNSTERBERG, 1991: 37). Jacques Aumont e Michel Marie (2003) definem o flashback justamente como um procedimento de ordenação da narrativa, em que uma cena do presente é sucedida por outra do passado. Dessa maneira, os autores o classificam como uma figura banal e não formal, que simplesmente "consiste em apresentar a narrativa em uma ordem que não é a da história" (AUMONT; MARIE, 2003: 131). Trata-se de um recurso já naturalizado, utilizado desde as primeiras mesas de montagem, e, por isso, facilmente reconhecido pelos espectadores.

Mas o que propomos aqui é desfazer a articulação anterior, em que o audiovisual e a lembrança se seccionam no flashback. Por uma via, essa desarticulação já havia sido realizada pelo próprio Munsterberg, ao apontar que nem sempre o emprego do procedimento está relacionado à memória de um personagem: pode tratar-se apenas de um retorno impessoal no tempo da narrativa. Assim, a lembrança seria uma subcategoria de flashback, a que Munsterberg considera mais interessante devido o seu caráter psicológico. Pois, segundo o autor, "há nele uma objetivação da função da memória. Neste sentido, o cutback apresenta um certo paralelismo com o close-up: neste identificamos o ato mental de prestar atenção, naquele, o ato mental de lembrar" (MUNSTERBERG, 1991: 37). Por outra via de articulação, entretanto, nos afastamos de Munsterberg, pois não consideramos que a representação do ato de lembrar seja limitada ao flashback. Em algumas estéticas audiovisuais, como veremos no decorrer do artigo, a lembrança é representada por outros procedimentos que não estão relacionados à ordenação das cenas: ela assume formas mais complexas e criativas. Essa desarticulação, que dirige a observação para além do flashback, é um movimento necessário para compreendermos a representação audiovisual da lembrança não apenas em relação aos seus usos narrativos, e sim voltados a sua forma em diferentes estéticas.

Quando utilizamos o termo "estética", nos referimos a expressão "estética cinematográfica", cunhada por Ismail Xavier (2005). O autor a emprega para designar um conjunto de proposições, de ordem teórico-ideológica, que orientam uma prática: "as diferentes estéticas [...] correspondem ao estabelecimento de determinados princípios gerais que se aplicam a diferentes modalidades de produção cinematográfica" (XAVIER, 2005: 15). A investigação do autor é regida por duas categorias principais de análise: a transparência, que remete aos casos em que o audiovisual produz um efeito ilusório de janela, constituindo uma relação "entre o mundo da representação artística e o mundo real" (XAVIER, 2005: 22); e a opacidade, em que, ao contrário, há uma separação radical entre este [o mundo da arte] e o mundo real" (XAVIER, 2005: 22). A partir desse par de oposição fundado na ideia de "realidade", Xavier discorre sobre as diferenças estéticas entre o cinema clássico (hegemônico) e os movimentos vanguardistas de épocas e localidades diversas. 
A discussão que empreendemos neste artigo parte, então, da seguinte questão: como podemos pensar a representação da lembrança a partir do par transparência/ opacidade, à medida que ela pertence ao âmbito da imaginação e não da realidade? Como base teórica para a reflexão (para entendermos as relações da lembrança com o mundo real), consideramos necessário apresentar uma breve descrição fenomenológica dos mecanismos de memória. Optamos pela filosofia de Henri Bergson (1990), pois se trata de um pensamento já articulado anteriormente ao cinema, por Gilles Deleuze (2007). Assim, num primeiro tópico, nos apropriamos de Bergson para descrever o fenômeno da lembrança. Esse aporte teórico sustem os tópicos seguintes, em que discorremos sobre a representação da lembrança em três estéticas descritas por Xavier: o naturalismo, o realismo e o antirrealismo.

\section{Fenomenologia da memória}

No livro Matéria e memória, Bergson (1990) destaca a dificuldade de uma definição precisa de memória, uma vez que utilizamos o conceito para caracterizar dois fenômenos distintos. O primeiro se constitui pelo aprendizado e tem relações com os mecanismos do corpo: é formado no esforço de repetições motoras. Esse tipo de memória manterá sempre um vínculo com a ação presente: dá-nos aquilo que precisamos para agir em determinado caso. Pode assim, ser definido mais precisamente pelo termo hábito do que por memória: "a bem da verdade, ela já não nos representa nosso passado, ela o encena; e, se ela merece ainda o nome memória, já não é porque conserve imagens antigas, mas porque prolonga seu efeito útil até o momento presente" (BERGSON, 1990: 63). O segundo tipo de memória, por sua vez, não está relacionado aos mecanismos motores e ao hábito, pois ao invés de recompor a totalidade da repetição, se volta à singularidade de cada momento. Trata-se de um ato em que deixamos o presente e nos colocamos no passado, na tentativa de resgatar um acontecimento vivido: "Para evocar o passado em imagens, é preciso poder abstrair-se da ação presente, é preciso dar valor ao inútil, é preciso querer sonhar" (BERGSON, 1990: 63-64). Esse segundo fenômeno, para o autor, é a memória verdadeira e faz jus ao termo lembrança. Bergson o descreve no seguinte trecho:

Temos consciência de um ato sui generis pelo qual deixamos o presente para nos colocar primeiramente no passado em geral, e depois numa certa região do passado: trabalho de tentativa, semelhante à busca do foco de uma máquina fotográfica. Mas nossa lembrança permanece ainda em estado virtual; dispomo-nos simplesmente a recebê-la, adotando a atitude apropriada. Pouco a pouco aparece como que uma nebulosidade que se condensasse; de virtual ela passa ao estado atual; e, à medida que seus contornos se desenham e sua superfície se colore, ela tende a imitar a percepção. Mas continua presa ao passado por suas raízes profundas, e se, uma vez realizada, não se ressentisse de sua virtualidade original, se não fosse, ao mesmo tempo que um estado presente, algo que se destaca do presente, não reconheceríamos jamais como uma lembrança (BERGSON, 1990: 110).

Esmiucemos essa citação com informações complementares do pensamento bergsoniano. Em primeiro lugar, para entender a fenomenologia de Bergson, é preciso desconstruir alguns usos da linguagem comum que evolvem a ideia de tempo. Pois, temos o costume de dizer que o passado "foi" e que o presente "é". Esta, porém, é uma armadilha linguística, uma vez que o passado se conserva e, portanto, não passa: o passado efetivamente "é". Por outro lado, o presente passa incessantemente: ao mesmo tempo em que é presente, já se tornou também passado. Essa efemeridade do presente faz Bergson considerá-lo como o nível mais contraído do passado: quando percebemos o presente, ele já não o é mais. O presente "foi". Isso implica dizer que no tempo, passado, presente e futuro não estão justapostos. O tempo não é cronológico. Há, na verdade, uma coexistência temporal: o passado coexiste com o presente que ele já foi, e o futuro é uma potência desse presente, imprevisível. 
Dessa forma, o ato de lembrar é descrito como um salto que vai do presente contraído até o passado conservado. Primeiramente, como aponta Bergson, nos colocamos no passado em geral, para depois procurar numa determinada região do passado, a lembrança que queremos evocar. Nesse momento, como conclui Deleuze (leitor de Bergson), duas coisas podem acontecer: "ou descubro ali o ponto que procurava, [...] ou não descubro porque ela está em outro lençol que me é inacessível" (DELEUZE, 1990: 150).

Surge, então, a necessidade de uma segunda desconstrução, referente ao local onde o passado se conserva. Imediatamente designamos o cérebro como órgão responsável pela função de armazenamento. Mas Bergson critica tal articulação. Para ele, a intercessão que fazemos entre memória e cérebro é arbitrária: não se deve admitir que o passado dependa de uma materialidade (o cérebro) para conservar-se. Bergson discorre sobre doenças cerebrais para testar sua hipótese de que tal faculdade não depende do cérebro. Além disso, as Neurociências não são capazes de definir uma região cerebral na qual as lembranças se conservariam. Logo, se não há uma seç̧ão natural, trata-se de uma falsa articulação. A solução que Bergson formula a essa questão é que a conservação do passado não é sequer uma faculdade, e que o passado se conserva em si. Bergson nomeia esse passado conservado de "lembrança pura".

O fenômeno da lembrança consiste, então, em uma atualização da lembrança pura em imagens formadas no presente: a imagem-lembrança. O termo imagem já nos indica que essa atualização é um trabalho de imaginação. Contudo, Bergson (1990: 111) alerta que a recíproca não é verdadeira e nem toda imaginação resulta numa imagem-lembrança: "Imaginar não é lembrar-se. Certamente uma lembrança, à medida que se atualiza, tende a viver numa imagem; mas [...] a imagem pura e simples não me reportará ao passado a menos que seja efetivamente no passado que eu vá buscá-la". É aqui que Bergson atribui ao cérebro a sua devida função: embora não seja responsável pela conservação do passado, ele executa o papel de evocação do passado através da imaginação. Por ser um órgão voltado à ação, é coerente pensar que nele resida a faculdade de "presentificação" do passado.

Vimos que Bergson define a imagem-lembrança como uma imagem formada no presente (criada pelo cérebro), mas que ao mesmo tempo não se desprende totalmente do passado: nós não a confundimos com o presente e a reconhecemos como lembrança. Eis a diferença em relação a outras imagens produzidas por nosso cérebro: as lembranças herdam a marca do passado. Não podemos afirmar, assim, que uma imagem-lembrança seja o passado em si, e sim que ela o representa. Dessa forma, Bergson destaca o momento presente como um estado atual e a imagem-lembrança como algo que, apesar de ser uma atualização, não se desprende de uma natureza virtual.

\section{A lembrança naturalista: convenções}

Xavier (2005) começa sua análise das estéticas cinematográficas pelo cinema clássico hollywoodiano. Apesar de a estética instaurada por esse cinema ser diretamente relacionada à representação da realidade, o autor prefere não utilizar o termo "realismo" para caracterizá-la, e sim opta por "naturalismo". Sua conclusão é que nos filmes clássicos a relação com a realidade não é propriamente de apreensão (registrar o real), na verdade, "a palavra de ordem é 'parecer verdadeiro'" (XAVIER, 2005: 41): a naturalização de um sistema de representação que fabrica a realidade. Para o autor, esse "efeito de janela" foi alcançado a partir de convenções na decupagem e na mise-en-scène (fundadas em métodos de montagem, intepretação, cenografia) que as tornam transparentes.

Em relação à representação do fenômeno da lembrança, do mesmo modo, a estética naturalista apresenta uma série de convenções resultantes de procedimentos de montagem e mise-en-scène. Vejamos como ocorre, então, a 
fabricação das imagens-lembranças naturalistas a partir dos casos mostrados pelas Figuras 1 e 2: flashbacks que pertencem as novelas A Favorita (Rede Globo, 2008) e $O$ cravo e a rosa (Rede Globo, 2000), que seguem regras inspiradas no padrão e nos efeitos do cinema clássico.

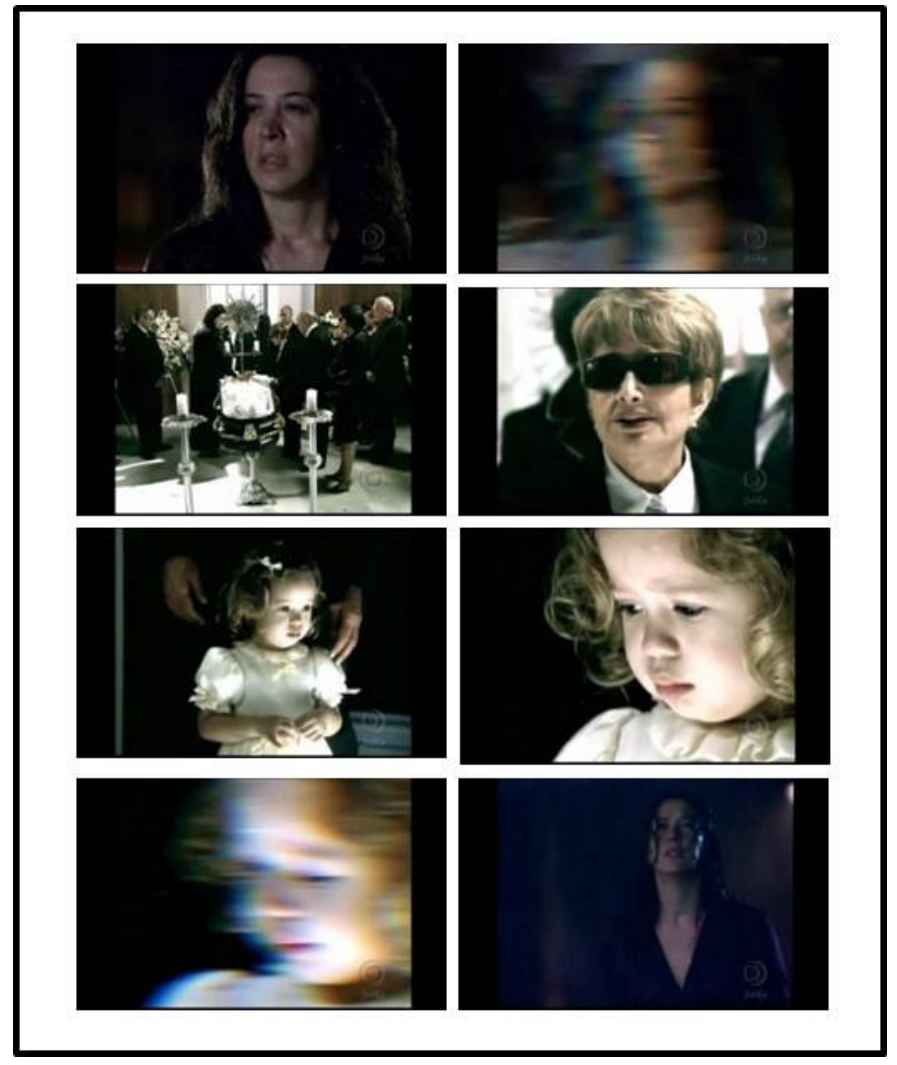

Figura 1: frames da novela A Favorita Fonte: imagens capturadas pelo autor

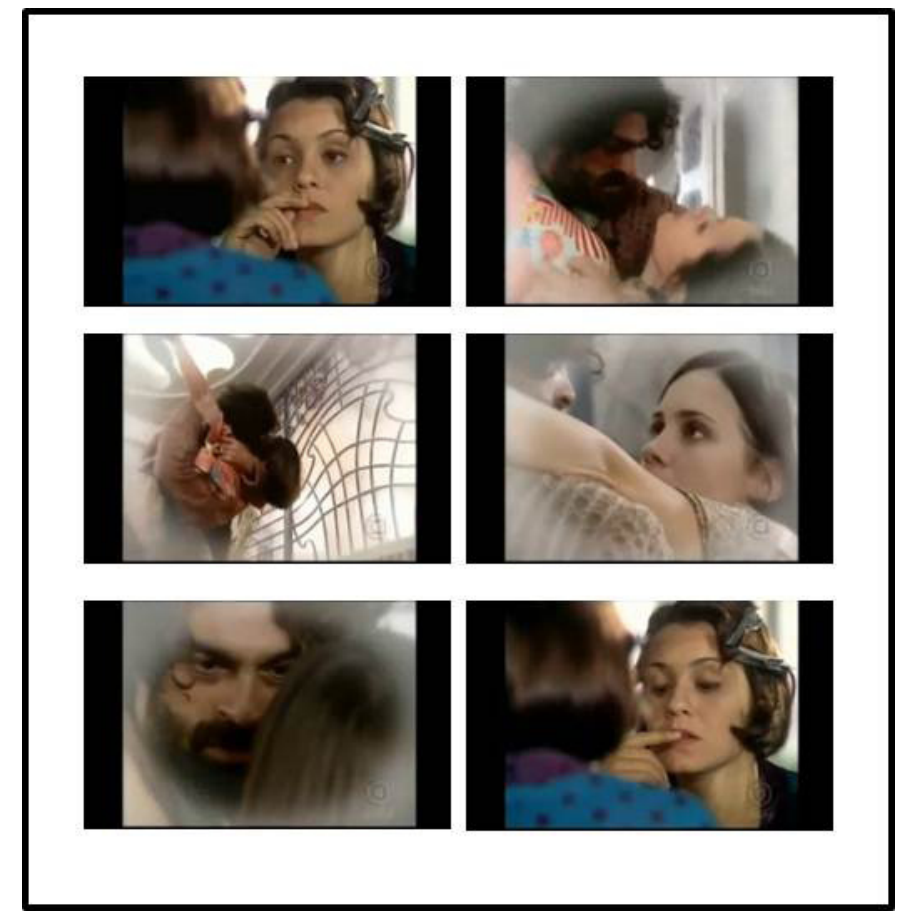

Figura 2: frames da novela O cravo e a rosa

Fonte: imagens capturadas pelo autor

Na sequência da novela $A$ favorita (Figura 1), temos o típico uso do flashback: o primeiro quadro apresenta o personagem que lembra no tempo presente; em seguida, ocorre um efeito de fusão de imagens, que faz a transição para as imagens-lembrança; até que o efeito de fusão se repete, e a imagem retorna 
ao tempo presente. Podemos atestar que as imagens do presente são, de fato, construídas a partir do princípio da transparência: no início, a cena possui uma fotografia (iluminação) tipicamente naturalista, que representa "um mundo real" e produz um efeito de presença. Porém, os quadros das imagens-lembrança seguem uma estética diferente: são compostos principalmente por tons de preto e branco, tanto o cenário, como o figurino e a iluminação, com uma luz branca intensa que vem do fundo. São esses procedimentos que produzem o efeito de lembrança: atribuem tanto um caráter psicológico (uma atmosfera de tristeza, de perda, pois se trata da lembrança de um velório), como estabelecem a distinção com o presente (a natureza virtual do passado).

Essa diferença estética entre a imagem presente (fundada no naturalismo) e a imagem-lembrança (fundada na imaginação) também aparece no segundo caso que destacamos, da novela $O$ cravo e a rosa (Figura 2). Existe, porém, uma diferença entre esses dois flashbacks, relacionada a uma categorização narratológica de Gerard Gennete (1980): o flashback da novela $A$ favorita é completivo, pois pertence ao tempo da história (traz uma informação nova, que ainda não havia sido apresentada na narrativa); já o flashback de $O$ cravo e a rosa é repetitivo, pertence ao tempo da narrativa (uma informação que já foi dada e é retomada). Em que essa classificação narrativa nos ajuda na análise estética? Somente um flashback completivo pode ser fabricado por procedimentos de mise-en-scène: a cena é gravada com a finalidade de ser uma lembrança. Esse processo não é possível no flashback repetitivo, em que a cena que retorna é um presente antigo da narrativa. Para tornar-se lembrança, é necessário modificar a imagem já gravada de forma naturalista, uma reciclagem da cena original.

$\mathrm{Na}$ cena da figura 2, a principal diferença entre as imagens do presente e as imagens-lembrança é uma espécie de névoa (inserida na imagem original por efeitos de pós-produção) que forma uma moldura. Do mesmo modo, essa imagem dá margem a uma leitura bergsoniana: a névoa não permite que a imagemlembrança se realize (a afasta do presente), representando o não desprendimento de sua natureza virtual. Outro procedimento que encaminha para a mesma interpretação é a inserção de efeitos sonoros, que produzem ecos nas vozes dos personagens, dando o sentido de um som que vem de longe. Ocorre também, nos casos de flashbacks repetitivos, uma psicologização das imagens: uma reedição que atribui um ritmo psicológico, conforme o sentimento da personagem que recorda.

Os flashbacks repetitivos, que reciclam imagens que remetiam originalmente a um tempo presente, também são utilizados com frequência no cinema. Mas é um recurso que ganha a sua "razão de ser" na teledramaturgia (e por isso trabalhamos com esses exemplos), já que a reciclagem de cenas aciona a serialização da narrativa: uma informação importante que aconteceu em capítulos anteriores pode ser repetida insistentemente para que os espectadores não a esqueçam.

Nos termos de Deleuze, os filmes naturalistas possuem letreiros que orientam: "atenção! lembrança" (DELEUZE, 2007: 64). Como vimos, ao ser fundada na transparência, essa estética utiliza procedimentos de mise-en-scène e montagem para dar opacidade aos momentos em que ocorre um afastamento do "mundo real" (o presente) em direção ao "mundo da imaginação" (no caso, o passado): as imagens-lembrança são fabricadas a partir da manipulação das cores das imagens (o uso do preto e branco ou qualquer mudança de coloração que se diferencie do tempo presente), dos efeitos de transição, da inserção de efeitos visuais (como bordas nas imagens) e sonoros, do uso dos elementos da encenação (iluminação, cenografia, figurino) e da reedição. Esses procedimentos criam símbolos que produzem o efeito de lembrança: representam a marca do passado (o não desprendimento da natureza virtual) e o caráter psicológico do ato. 


\section{A lembrança realista: herança da lembrança pura}

A ideia de realismo no cinema admite diferentes definições. Vimos que no cinema clássico, que faz uma fabricação do real, Xavier (2005) opta pelo termo naturalismo, referindo-se à naturalização da decupagem e da mise-en-scène. Xavier descreve, então, duas estéticas cinematográficas que, para ele, merecem ser nomeadas de realistas. A primeira é o "realismo crítico", cuja teoria e prática rementem aos cineastas dos anos 20, como Sergei Eisenstein e Vsevold Pudovkin, entre outros. Nela, o conceito de real não remete ao mundo natural, visível e palpável, tal como é definido pelo cinema clássico. Ao contrário, o real significa aquilo que não é visível de imediato, às inter-relações entre diferentes fenômenos: remete aos fatos sociais e não ao mundo natural. Foi através do processo de montagem que o realismo crítico encontrou uma forma de dar significação a essas relações dialéticas.

A segunda estética que Xavier classifica como realista é a que denomina "realismo revelatório". Sua base teórica, de acordo com o autor, foi formulada principalmente por André Bazin e sua prática encontra-se nos filmes de Orson Welles, Jean Renoir e no Neorrealismo italiano. A noção de real empregada refere-se a uma apreensão, um registro, de forma que não haja intervenção no mundo filmado: "implica na minimização do sujeito do discurso, de modo a deixar o mundo visível captado transparecer o seu significado" (XAVIER, 2005: 75). Dessa forma, o realismo revelatório critica tanto o cinema naturalista, por fabricar o real através de convenções, como o realismo crítico, pelo caráter manipulatório da montagem. Por isso mesmo, nessa nova concepção de realismo, os principais procedimentos utilizados foram a profundidade de campo e o plano-sequência. Como define Deleuze (2007: 09): "o real não era mais representado ou reproduzido, mas visado".

Partindo desses diferentes empregos da noção de realismo no cinema, é preciso fazer algumas considerações para delimitarmos o que seria uma lembrança realista. Em primeiro lugar, pelo prisma do realismo crítico, a lembrança também é representada por procedimentos de montagem. Por segundo, não identificamos uma recorrência de analepses no neorrealismo italiano. Assim, entre os diretores realistas listados por Xavier, parece-nos que Orson Welles foi o que mais avançou em utilizar a lembrança fora de sua representação naturalista. Outro diretor que seguiu por esse caminho foi Joseph L. Mankiewicz, a quem Deleuze (2007: 64) atribuiu o título de "maior autor do flashback". Propomos, então, uma estética realista da lembrança com base na análise dos filmes desses dois autores.

Como sabemos, a narrativa do célebre filme de Welles, Cidadão Kane (Citizen Kane, 1941), é construída a partir do segredo em torno da última palavra que o personagem principal, o magnata Charles Foster Kane, proferiu antes de morrer: rosebud. Na trama, um jornalista investiga, a partir da realização de entrevistas, o significado deste termo: o filme passa a apresentar uma série de flashbacks de vários personagens que conviveram com Kane em momentos diferentes da sua vida. Mankiewicz, por sua vez, apresenta uma estrutura narrativa semelhante no filme A malvada (All about Eve, 1950). Na primeira cena, vemos a entrega de um prêmio de melhor atriz de teatro para a personagem Eve Harrington. Antes de mostrar Eve, porém, Mankiewicz enquadra individualmente alguns personagens que estão na plateia: é a partir de suas lembranças que ficamos sabendo tudo sobre a personagem Eve (como prometido no título em inglês). O filme passa a apresentar, então, flashbacks de três personagens, que revelam como Eve traiu sua mentora e conquistou seu lugar no teatro, como tentou seduzir o marido de uma amiga etc.. Apresenta-se ao espectador, assim, o verdadeiro caráter da personagem (ela é "a malvada" do título em português).

Há uma diferença entre as lembranças naturalistas e as que aparecem nestes dois filmes, que foi apontada por Deleuze. Enquanto no cinema clássico, o flashback" 
só assegura a progressão de uma narração linear" (DELEUZE, 2007: 64), nos filmes de Welles e Mankiewicz, um segredo inexplicável o impõe: não é mais possível contar a história no presente. É a partir dessa diferença narrativa essencial que podemos compreender a estética dos flashbacks de Cidadão Kane e A malvada. Em nenhum dos dois casos, as lembranças são representadas a partir da facilidade dos símbolos próprios do naturalismo. Isso porque as lembranças criadas por Welles e Mankiewicz não se fundam nas imagens-lembranças, e sim na lembrança pura: não é a representação do passado e o caráter psicológico da lembrança que importam, mas o ato de busca, de percorrer pelos diferentes lençóis do passado conservado. Por isso que são vários personagens que relembram: cada flashback significa o acesso a uma região diferente do passado. Como aponta Deleuze (2007: 130), sobre Cidadão Kane especificamente: "Cada uma [região do passado] tem o que Bergson chama de 'pontos brilhantes', singularidades, mas cada uma recolhe em torno de todos desses pontos a totalidade de Kane ou sua vida inteira como uma 'vaga nebulosidade'".

Deleuze destaca alguns procedimentos audiovisuais que reforçam a relação desses dois filmes com a lembrança pura. Primeiramente, o autor discorre sobre o uso do extracampo nos flashbacks de $A$ malvada. Pois, à medida que o caráter de Eve é narrado pela memória de outros personagens, nenhum flashback poderia apresentá-la em um momento solitário. Como Eve sempre contracena com outros nos flashbacks, ela nunca deixa de encenar uma personalidade falsa. Para descobrir quem ela realmente é, era preciso que ela estivesse só. Mankiwicz encontra uma solução: coloca, em duas cenas, o personagem recordador no extracampo, sem que Eve perceba sua presença. "É o papel do espião, ou da testemunha involuntária, que dá, ao cinema de Mankiewicz, toda a sua força: nascimento visual e auditivo da memória" (DELEUZE, 2007: 68). Assim, o filme passa a ser uma procura, entre as diversas regiões do passado apresentadas, dos "pontos brilhantes" em que Eve mostrou sua verdadeira personalidade.

Em segundo lugar, Deleuze destaca também o uso da profundidade de campo na composição dos flashbacks de Cidadão Kane, pois afirma que o procedimento permite uma verdadeira exploração de uma imagem como um lençol do passado: "as imagens em profundidade expressam regiões do passado como tal, cada um com seus acentos próprios ou seus potenciais" (DELEUZE, 2007: 130).

Dessa maneira, como vimos nesses dois casos, há um afastamento da estética naturalista da lembrança: a simples representação da marca do passado através de convenções. Vemos, na verdade, o uso de procedimentos mais complexos, como a profundidade de campo e o extracampo. Defendemos, assim, que uma estética realista da lembrança é aquela em que a natureza virtual não é representada, e sim herdada diretamente da lembrança pura.

\section{A lembrança antirrealista: a superação da dualidade}

A classificação de estética "antirrealista" compreende, para Xavier (2005), um conjunto de vanguardas cinematográficas que se opunham a tradição clássica de pensar a arte como imitação (mimese): os diferentes "ismos", impressionismo, expressionismo, surrealismo. O que une esses projetos artísticos é o fato de serem "contra a ideia da reprodução natural", e a busca por "provocar estranheza, que denuncia sua presença ostensiva como objeto não natural e trabalhado" (XAVIER, 2005: 100). Mas o autor afirma que a classificação de antirrealista não significa que essas vanguardas se afastem da ideia de real: um artista impressionista, por exemplo, acredita que seu modo de representação é mais fiel às sensações reais do que o modelo clássico. Dessa maneira, o antirrealismo não implica em um afastamento do real: a diferença é que a relação com o real é traçada por meio da categoria da opacidade, e não da transparência. São, assim, imagens que pretendem ser mais reais "do que o real captado e organizado pelo senso comum" (XAVIER, 2005: 100). 
Passamos, então, à análise de algumas representações da lembrança em obras contemporâneas que foram inspiradas por essas vanguardas antirrealistas. Veremos que há nelas uma recusa do convencional procedimento do flashback, que é substituído por técnicas que remetem ao impressionismo e expressionismo. A primeira delas é uma cena do filme Kill Bill vol. 1 (2003), de Quentin Tarantino, reproduzida na Figura 3.

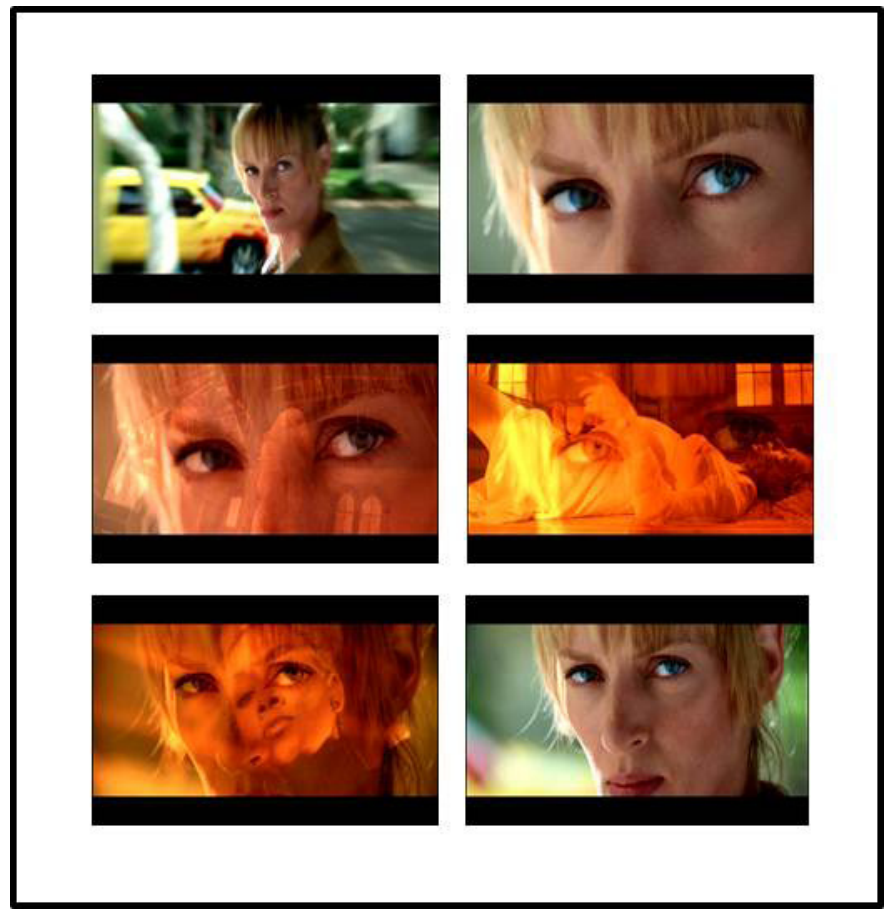

Figura 3: frames do filme Kill Bill vol.1

Fonte: DVD Kill Bill vol.1

Em Kill Bill, a personagem "A noiva" quer se vingar das cinco pessoas responsáveis pelo massacre ocorrido durante o seu casamento, que resultou na morte de todos os convidados e a deixou em coma por quatro anos. Na cena mostrada na Figura 3, quando a personagem encontra uma dessas pessoas, forma-se instantaneamente um circuito com imagens-lembrança do dia do massacre. Para retornar ao passado da narrativa, entretanto, Tarantino não opera por um flashback convencional, num simples corte de uma cena do presente para outra do passado. Ele lança mão de dois procedimentos típicos do cinema impressionista: o primeiro é o enquadramento em primeiro plano dos olhos da personagem; o segundo é a sobreposição de planos do presente e do passado, de forma que congreguem um mesmo quadro. No impressionismo, segundo Xavier, esses procedimentos eram utilizados como forma de "experimentar, pela montagem e pelos enquadramentos cinematográficos, as várias ficções possíveis, as várias ordens que definiriam realidades imaginárias" (XAVIER, 2005: 111).

Não ocorre nessa cena de Kill Bill uma recusa total do procedimento do flashback: ele apenas deixa de estar justaposto à cena do presente, e é montado

${ }^{1}$ Jargão que remete à linha do tempo própria dos softwares de edição. Enquanto que a montagem tradicional é produzida numa justaposição, o efeito de sobreposição é resultante de um posicionamento vertical dos planos. de forma vertical ${ }^{1}$. Com isso, o filme reforça o paralelo que, como vimos, já havia sido traçado por Munsterberg, entre o caráter psicológico do primeiro plano e do flashback. Mas o êxito desse procedimento reside em conseguir representar de forma mais precisa o fenômeno descrito por Bergson (1990), em que passado e presente nunca estão justapostos: a percepção é sempre dada num misto entre o presente (mundo material) e as imagens-lembranças. O uso desses procedimentos para a representação da memória seguem, assim, os postulados impressionistas, em que: "A unidade do espaço é uma ficção em nossa cabeça. [...] O cinema é uma reeducação pelo absurdo. Principalmente quando o cineasta sabe organizar o material de modo a produzir uma ficção mágica capaz de deflagrar a experiência reveladora" (XAVIER, 2005: 110). 
Outras imagens-lembrança que classificamos como antirrealista pertencem a minissérie Capitu (Rede Globo, 2008), dirigida por Luiz Fernando Carvalho. Sua narrativa é estruturada da mesma forma que o romance Dom Casmurro, no qual ela se baseia: um personagem-narrador (Dom Casmurro) que escreve um livro das suas memórias. Contudo, ao invés de isolar o narrador no polo presente do flashback, Carvalho optou por fabricar suas lembranças utilizando procedimentos inspirados no cinema expressionista, como analisamos a seguir, a partir dos frames das Figura 4.

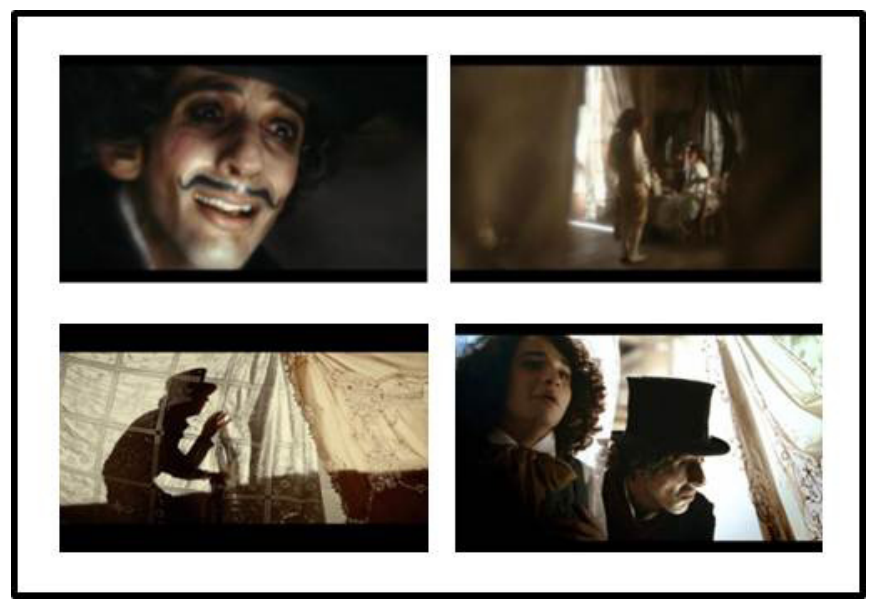

Figura 4: frames da minissérie Capitu Fonte: DVD Capitu

Comecemos pelo terceiro frame da Figura 4. Ele apresenta a sombra do personagem Dom Casmurro percorrendo por um cenário composto de lençóis estendidos. Essa imagem tem uma evidente ligação com a fenomenologia de Bergson. Como vimos, o termo "lençol" é utilizado recorrentemente por Deleuze como uma metáfora que remete às regiões acessíveis do passado em que nos colocamos para evocar uma imagem-lembrança. Assim, a representação da lembrança em Capitu tem proximidade com a estética realista (os filmes de Welles e Mankiewicz), pois herda sua virtualidade da própria lembrança pura. Contudo, Carvalho recusa o procedimento do flashback e opta por técnicas mais criativas, o que o afasta do realismo.

A primeira delas pode ser vista nos dois primeiros frames da Figura 4, em que Dom Casmurro finalmente encontra a lembrança que quer evocar. $\mathrm{O}$ primeiro frame, então, enquadra o olhar do personagem, e o seguinte apresenta a imagem da sua visão. Ou seja, temos aqui um raccord formado no olhar, procedimento que no cinema é nomeado de campo/contracampo. Contudo, no segundo quadro (no contracampo), aparece ele mesmo, só que num tempo passado: estaria, então, o personagem, literalmente, vendo a si mesmo no passado? O que ocorre aqui é uma operação do flashback por meio do campo/contracampo, o que permite, assim, a interpretação de uma materialização do passado no presente. Sabemos que o campo/contracampo é um procedimento que faz parte da decupagem do cinema clássico, cuja função está relacionada principalmente à representação do espaço. Carvalho, entretanto, o opera de forma criativa, seguindo a tendência expressionista de "quebrar a continuidade do espaço" (XAVIER, 2005: 102) e utilizando-o para a espacialização da memória. Porém, por mais que essa operação encaminhe essa interpretação, ainda se mantém a polaridade do flashback: o presente (campo) e o passado (contracampo).

É no quarto frame da Figura 4 que a minissérie supera essa dualidade, pois vemos o personagem em dois tempos distintos da narrativa: Dom Casmurro na velhice e na juventude. Ao invés de montar os tempos em duas cenas (seja de forma justaposta ou vertical), Carvalho opta por montá-los no interior de um mesmo plano, na mise-en-scène. Esse procedimento também remete a vanguarda 
expressionista, pois possibilita "atravessar a superfície material e atingir a comunicação direta das forças espirituais dentro de cada um de nós." (XAVIER, 2005: 102). Dessa forma, ao recusar totalmente a polaridade do procedimento do flashback na representação do ato de lembrar, a minissérie cria imagens expressionistas de memória, que superam a dualidade do mundo.

\section{Considerações finais}

Após analisar as estéticas audiovisuais do fenômeno da lembrança e marcar suas diferenças em relação às categorias da opacidade e transparência, chegamos a duas conclusões. A primeira derruba a definição de Aumont e Marie (2003) sobre o caráter não formal do flashback: os autores parecem ignorar sua articulação natural com a memória, apontada por Munsterberg (1991) nos primórdios da teoria, que lhe atribui características fenomenológicas e psicológicas. Vimos que no cinema naturalista, esse tipo de flashback é formado a partir de símbolos visuais e sonoros. Já no realismo revelatório, a profundidade de campo e o extracampo se relacionam à lembrança pura; na estética antirrealista, o flashback pode ser montado de forma vertical (numa representação impressionista).

Em segundo lugar, reiteramos que nem sempre a lembrança se dará na forma de um flashback. As últimas representações que analisamos, da minissérie Capitu, não formam o circuito presente/imagem-lembrança na montagem de duas cenas, e sim montam tempos distintos num mesmo espaço: para isso, foram utilizados o campo/contracampo e a montagem no interior de um plano (pela mise-en-scène). Esse tipo de visualização, que se aproxima da vanguarda expressionista, é capaz de superar a dualidade própria do flashback. Portanto, a relação entre o ato de lembrar e o audiovisual deve ser compreendida para além deste procedimento.

\section{Referências bibliográficas}

AUMONT, Jacques; MARIE, Michel. Dicionário teórico e crítico de cinema. Campinas: Papirus, 2003.

BERGSON, Henri. Matéria e memória: ensaio sobre a relação do corpo com o espírito. São Paulo: Martins Fontes, 1990.

DELEUZE, Gilles. A imagem-tempo. São Paulo: Brasiliense, 2007.

GENETTE, G. Discurso da narrativa. Lisboa: Veiga, 1980.

MUNSTERBERG, Hugo. A memória e a imaginação. In: XAVIER, Ismail (org.) $A$ experiência do cinema. Rio de Janeiro: Edições Graal, 1991.

XAVIER, Ismail. $O$ discurso cinematográfico: a opacidade e a transparência. São Paulo: Paz e Terra, 2005. 